\title{
From the Editor: Present Realities and Future Directions
}

\author{
Dorothy S. Becvar
}

Published online: 29 April 2010

(C) Springer Science+Business Media, LLC 2010

At the Fall 2009 Annual Conference of the American Association for Marriage and Family Therapy (AAMFT) I gave a plenary session entitled "Providing News of Difference: Family Therapy Through the Years." In addition to looking at the history of the field as well as providing a consideration of present realities I was asked to focus particularly on future directions for family therapy. Indeed, being the editor of a journal enables me to have a perspective on trends of which I might otherwise not be aware. One of the first focal issues I named relative to the future was that of spirituality and religion. Noting the landmark article by Prest and Keller (1993), in which attention was called to the need for greater awareness of spirituality and religion in the context of therapy, I shared my perception that this was an area that is growing and will continue to do so as more and more researchers and practitioners engage in explorations related to this topic. Consistent with my assessment, the first half of this issue includes four unsolicited articles that are devoted to topics with a spiritual and/or religious orientation. What is more, several others are currently in the pipeline.

In the first article, "Bowen Family Systems Theory and Spirituality: Exploring the Relationship Between Triangulation and Religious Questing," Katie Heiden Roots, Peter Jankowski, and Steven Sandage focus on spirituality and seek integration relative to the concepts of differentiation and triangulation. In the second article, also utilizing a Bowenian perspective, Yeo Jin Ahn and Marianne Miller ask, and respond in the affirmative, to the question, "Can MFTs Address Spirituality with Clients in Publically Funded Agencies?" Next, focusing on the clergy and the larger religious context, Maureen Davey, Argie Allen, and Adam Davey have contributed an article entitled, "Being Examples to the Flock: The Role of Church Leaders and African American Families Seeking Mental Health Care Services." The section on Spirituality/Religion then concludes with an exploration of a particular spiritual practice, which is described in the article, "Voices of Experienced Meditators: The Impact of Meditation Practice on Intimate Relationships," authored by Eric McCollum and Irene Paz Pruitt.

D. S. Becvar (ه)

School of Social Work, Saint Louis University, St. Louis, MO, USA

e-mail: becvards@slu.edu 
The four additional articles that comprise the General Interest section of this issue also speak to various areas that I believe will receive greater attention as we move forward into the future. For example, the article entitled, "Describing Latinos Families and Their Help Seeking Attitudes: Challenging the Family Therapy Literature" by Maria Bermudez, Dwight Kirkpatrick, Lorona Hecker, and Carmen Torres-Robles, illustrates the need for as well as the increased attention being given to the issues of cultural sensitivity and cultural competence. Shifting to a consideration of relationships, Jamie Banker, Christine Kaestle, and Katherine Allen focus on the youth in our society and conclude with the statement/ title, "Dating is Hard Work: A Narrative Approach to Understanding Sexual and Romantic Relationships in Young Adulthood." Focusing on the next stage in relationship development along with a consideration of the larger context, Liat Kulik and Hagit HavushaMorgenstern provide a report on "An Ecological Approach to Explaining Women's Adjustment in the Initial Stage of Marriage," a study that was undertaken in Israel. Finally, responding to a topic of concern-past, present, and future-Steven Sandage considers "Intergenerational Suicide and Family Dynamics: A Hermeneutic Phenomenological Case Study."

I also believe that the use of both qualitative and quantitative methodologies throughout this issue reflects an increasing acceptance of and respect for the many ways of knowing that each represents. I anticipate that this, too, will be an important aspect of research in the future. Similarly, greater awareness of and a focus on the larger ecological context, as evidenced in several of this issue's articles, is a trend that is likely to continue to evolve. And the ongoing development of theoretical models created by some of the early theorists and therapists is always cause for consideration and celebration. Indeed, I look with admiration on the accomplishments of the past, I take pride in present developments in the field of family therapy, and I anticipate with great excitement the potentials and possibilities of the future.

\section{References}

Prest, L. A., \& Keller, J. F. (1993). Spirituality and family therapy: Spiritual beliefs, myths, and metaphors. Journal of Marital and Family Therapy, 19(20), 137-148. 